08

\title{
Влияние электромагнитного поля промышленной частоты на физико-химические свойства микро- и нанопорошков алюминия
}

\author{
() А.В. Мостовщиков, ${ }^{1-3}$ Д.В. Тихонов, ${ }^{1}$ Ю.С. Приходько ${ }^{2}$ \\ ${ }^{1}$ Национальный исследовательский Томский политехнический университет, \\ 634050 Томск, Россия \\ ${ }^{2}$ Томский государственный университет систем управления и радиоэлектроники, \\ 634050 Томск, Россия \\ ${ }^{3}$ Томский государственный архитектурно-строительный университет, \\ 634003 Томск, Россия \\ e-mail: pasembellum@mail.ru
}

Поступило в Редакцию 24 марта 2021 г.

В окончательной редакции 3 мая 2021 г.

Принято к публикации 4 мая 2021 г.

Исследовано влияние электромагнитного поля промышленной частоты $50 \mathrm{~Hz}$ на изменение физикохимических свойств порошков алюминия различной дисперсности. Установлено, что вследствие воздействия поля увеличивается их сорбционная способность, что приводит к значительному изменению свойств порошков алюминия.

Ключевые слова: порошки алюминия, вихревые токи, токи Фуко, адсорбция, старение порошков.

DOI: 10.21883/JTF.2021.09.51222.77-21

\section{Введение}

Порошки алюминия различной дисперсности используются в аддитивных и порошковых технологиях изготовления конструкционных деталей машин и механизмов, катализаторов, добавок в пиротехнические составы и ракетные топлива и др. [1-11]. Реакционную способность повышают за счет увеличения дисперсности порошков, площади удельной поверхности [12] или введения активных добавок [13], которые иногда являются нежелательными примесями. Известно, что реакционная способность порошков алюминия повышается при воздействии электромагнитного СВЧ излучения [14], электронных пучков [15] и др. Экспериментально установлено, что при длительном хранении нанопорошков металлов в полиэтиленовой условно герметичной таре их реакционная способность также возрастает [16]. Таким образом, в многочисленных экспериментальных работах показано, что микро- и нанопорошки металлов являются восприимчивыми к внешним электромагнитным воздействиям. Вместе с тем не изучено влияние электромагнитных полей промышленной частоты на физико-химические свойства порошков алюминия, в то время как в процессе их производства, транспортировки, хранения они, безусловно, подвергаются воздействию таких полей. В то же время общеизвестно, что воздействие переменного электромагнитного поля на металл приводит к возникновению в металле вихревых токов Фуко. Учитывая, что порошки металлов (особенно нанопорошки) являются структурами с метастабильным состоянием защитной пассивирующей оболочки $[17,18]$, возникновение таких токов в частицах порошка должно приводить к заметному изменению их физико-химических свойств.

Целью настоящей работы являлось исследование закономерностей изменения физико-химических свойств микро- и нанопорошков алюминия (МПА и НПА соответственно) после воздействия переменного магнитного поля частотой $50 \mathrm{~Hz}$.

\section{1. Методики экспериментов и характеристики образцов}

В настоящей работе использовали электровзрывной нанопорошок алюминия (НПА) марки Alex, среднеповерхностный диаметр частиц составлял $90 \mathrm{~nm}$, площадь удельной поверхности $\sim 14 \mathrm{~m}^{2} / \mathrm{g}$. В качестве микронного порошка алюминия (МПА) использовали порошок марки ASD-6M, полученный методом распыления расплавленного алюминия. Среднеповерхностный диаметр частиц составлял $3.5 \mu \mathrm{m}$, а площадь удельной поверхности $\sim 0.6 \mathrm{~m}^{2} / \mathrm{g}$. Все исследуемые порошки были слабо агломерированы, а их частицы покрыты с поверхности оксидной оболочкой. Содержание металлического алюминия составляло в микронном порошке ASD-6M 93 wt.\%, а в НПА - 90 wt.\%.

Обработку образцов проводили с использованием установки, схема которой приведена на рис. 1. Для генерации электромагнитного поля использовали медную шину, в которой создавали ток силой 100, 300 и 600 А. Напряженность магнитного поля определяли с помощью измерителя напряженности поля промышленной частоты П3-50 в точке на расстоянии $247 \mathrm{~mm}$ от поверхности шины, а затем по измеренным величинам проводили 


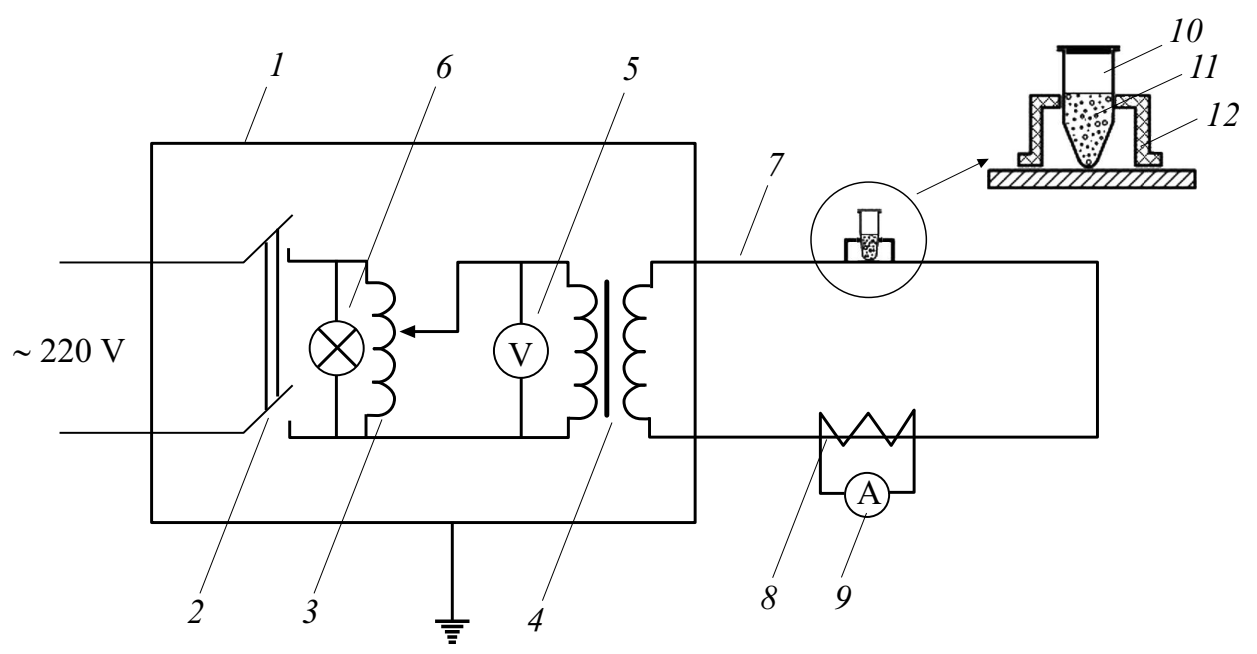

Рис. 1. Схема экспериментальной установки для обработки порошков магнитным полем промышленной частоты: $1-$ заземленный корпус, 2 - автоматический выключатель, 3 - автотрансформатор, 4 - понижающий трансформатор, 5 - вольтметр, 6 - контрольная лампа, 7 - токоведущая шина, 8 - трансформатор тока, 9 - амперметр, $10-$ пробирка, $11-$ порошок, 12 - держатель.

расчет напряженности поля в середине образца, т.е. в точке, удаленной на $8 \mathrm{~mm}$ от поверхности шины по формуле

$$
H_{2}=\frac{r_{1}}{r_{2}} H_{1},
$$

где $r_{1}-$ расстояние от шины до точки 1 (247 mm), $r_{2}$ - расстояние от шины до центра образца $(8 \mathrm{~mm})$, $H_{1}$ - модуль напряженности магнитного поля, измеренный в точке на расстоянии $247 \mathrm{~mm}$ от поверхности шины. Выбор расстояния $247 \mathrm{~mm}$ обусловлен тем, что это минимальное расстояние антенны-преобразователя измерителя промышленной частоты П3-50 от шины, при котором не происходило „зашкаливания“ на максимальном диапазоне измерений; $8 \mathrm{~mm}$ - расстояние от шины до центра образца в пробирке, так как образцы засыпали на высоту $16 \mathrm{~mm}$ (от дна пробирки), и пробирки располагались вплотную и вертикально по отношению к шине, как это показано на рис. 1. Измеренные значения электрической составляющей поля на расстоянии $247 \mathrm{~mm}$ от поверхности шины и в непосредственной близости от шины не превышали значения $0.4 \mathrm{~V} / \mathrm{m}$. Порошок помещали в полиэтиленовую пробирку диаметром $10 \mathrm{~mm}$, а затем обработку образца осуществляли в течение $20 \mathrm{~min}$ в открытой пробирке при свободном доступе воздуха.

Глубину проникновения переменного электромагнитного поля в образец (т.е. предельную глубину, на которой еще возможно индуцирование вихревых токов Фуко) рассчитывали по формуле [19]:

$$
\delta=\frac{1}{\sqrt{\pi f \mu \mu_{0} \sigma}},
$$

где $f$ - частота колебаний магнитного поля проводника $(50 \mathrm{~Hz}), \sigma$ - удельная электропроводность алюминиевого порошка $(35.4 \mathrm{MS} / \mathrm{m}), \mu$ - относительная магнитная проницаемость алюминия $(\sim 1), \mu_{0}-$ магнитная проницаемость вакуума $\left(4 \pi \cdot 10^{-7} \mathrm{H} / \mathrm{m}\right)$. Глубина проникновения поля составляла не менее $\sim 12 \mathrm{~mm}$ для массивного металлического образца. Учитывая, что порошок алюминия обладает высокой дисперсностью, а также то, что в порошке значительный объем насыпки составляют воздушные поры, в которых экранирования электромагнитного поля не происходит (скин- эффект не возникает), порошки алюминия в пробирке диаметром $10 \mathrm{~mm}$ в процессе облучения полностью подвергались воздействию поля.

Для количественного определения изменения физикохимических свойств порошков металлов применяли метод дифференциального термического анализа [20] с использованием термоанализатора Q600 SDT (TA Instruments, USA).

\section{2. Экспериментальные результаты и обсуждение}

В таблице (колонки НПА) представлены результаты исследования физико-химических свойств нанопорошка алюминия после воздействия переменного электромагнитного поля.

Согласно данным таблицы, после воздействия электромагнитного поля с ростом напряженности магнитной составляющей поля происходило увеличение содержания сорбированных поверхностью частиц газов. Учитывая, что процесс обработки полем происходил при свободном доступе воздуха, а процесс десорбции газов продолжался при нагревании порошков до $\sim 300^{\circ} \mathrm{C}$, наиболее вероятным десорбируемым веществом являлась сорбированная и конституционно-связанная вода. Наиболее вероятным является следующее объяснение. 
Физико-химические свойства НПА и (МПА) до и после обработки электромагнитным полем промышленной частоты

\begin{tabular}{|c|c|c|c|c|c|c|c|c|c|}
\hline \multirow{2}{*}{$\begin{array}{c}\text { № } \\
\text { образца }\end{array}$} & \multirow{2}{*}{$\begin{array}{c}\text { Напряженность } \\
\text { магнитного } \\
\text { поля, kA/m }\end{array}$} & \multicolumn{2}{|c|}{$\begin{array}{c}\text { Доля десорбированных газов } \\
\text { в \% от начальной массы }\end{array}$} & \multicolumn{2}{|c|}{$\begin{array}{c}\text { Температура начала } \\
\text { окисления, }{ }^{\circ} \mathrm{C}\end{array} \mid$} & \multicolumn{2}{|c|}{$\begin{array}{c}\text { Максимальная скорость } \\
\text { окисления, } \mathrm{mg} / \mathrm{min}\end{array}$} & \multicolumn{2}{|c|}{$\begin{array}{c}\text { Удельный тепловой эффект } \\
\text { окисления, kJ/g }\end{array}$} \\
\hline & & НПА & МПА & НПА & МПА & НПА & МПА & НПА & МПА \\
\hline 1 & - & 1.32 & 0.87 & 367.1 & 366.1 & 0.100 & 2.687 & 9.37 & 11.69 \\
\hline 2 & 1.33 & 1.65 & 1.40 & 344.2 & 439.9 & 0.078 & 0.220 & 11.24 & 10.27 \\
\hline 3 & 2.79 & 3.34 & 2.92 & 399.0 & 484.6 & 0.055 & 0.197 & 12.46 & 12.42 \\
\hline 4 & 5.11 & 3.47 & 2.29 & 391.2 & 488.7 & 0.079 & 0.193 & 11.22 & 11.07 \\
\hline
\end{tabular}
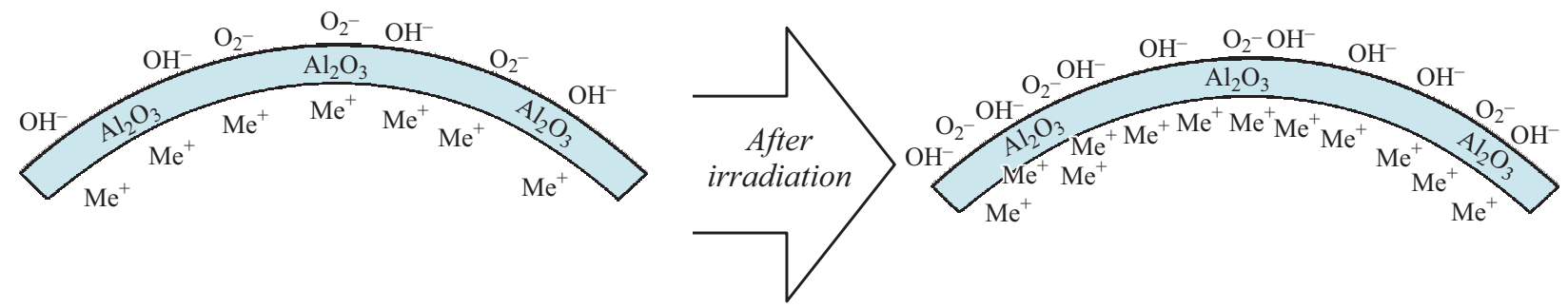

Рис. 2. Схема процесса сорбции на поверхности частицы после облучения.

При действии электромагнитного поля на частицы в них индуцируются вихревые токи, что приводит к изменению электрического потенциала на поверхности частиц. Это, в свою очередь, стимулирует процессы сорбции воды поверхностью частиц, покрытой оксидным слоем. На оксидной поверхности частиц облегчен процесс диссоциации воды, который протекает по схеме (1):

$$
\mathrm{H}_{2} \mathrm{O} \rightarrow \mathrm{H}^{+}+\mathrm{OH}^{-}
$$

В дальнейшем протон, проникая в металлическую составляющую частицы, восстанавливается, захватывая электрон из металла (по схеме 2) и способен выйти из частицы, не нарушая ее зарядовой нейтральности:

$$
\mathrm{H}^{+}+e^{-} \rightarrow \mathrm{H}^{0} .
$$

Схематически этот процесс показан на рис. 2. Таким образом, вследствие воздействия в металлическом ядре частицы индуцируется избыточный положительный заряд, который компенсируется отрицательным зарядом накапливающихся на поверхности частицы $\mathrm{OH}^{-}$-групп. Этот механизм коррелирует с ранее установленным подобным механизмом, протекающим при воздействии короткоимпульсного СВЧ излучения [14].

Температура начала окисления нанопорошка при этом (см. таблицу) не имела четко выраженной зависимости от внешнего воздействия: она снижалась для образца 2 на $22.9^{\circ} \mathrm{C}$, а для образцов 3 и 4 увеличивалась на 31.9 и $24.1^{\circ} \mathrm{C}$ соответственно.

Скорость окисления образцов после воздействия в целом снижалась. Это коррелирует с данными об увеличении доли сорбированных поверхностью молекул воды - поверхность частиц порошка становится менее проницаема для окислителя и вследствие этого процесс окисления протекает медленнее.

При всех режимах воздействия электромагнитным полем наблюдается увеличение удельного теплового эффекта окисления. Наибольший его рост зафиксирован у образца 3 (на $32.9 \%$ ), а у образцов 2 и 4 он составил 19.9 и $19.8 \%$ соответственно. Вероятной причиной роста величины удельного теплового эффекта окисления является увеличение теплоты реакции окисления вследствие того, что в ней участвует металлический порошок с индуцированным на нем избыточным положительным зарядом. То есть упрощенно это можно понимать, как реакцию окисления $\mathrm{Al}^{+}+\mathrm{O}_{2}$, а не обычную реакцию окисления $\mathrm{Al}^{0}+\mathrm{O}_{2}$. Участие в такой окислительновосстановительной реакции положительного иона алюминия вместо нейтрального атома снижает энергетический барьер реакции, что и приводит к заметному увеличению удельного теплового эффекта окисления, установленному как в настоящей работе, так и в предыдущих $[14,15]$.

Аналогичным образом был исследован микронный порошок алюминия.

Согласно данным таблицы (колонки МПА), с ростом напряженности магнитного поля, так же как и в НПА, происходило увеличение количества десорбированных газов, что указывает на аналогичную физическую природу протекающих в микронном порошке процессов.

После обработки микронного порошка алюминия происходило увеличение температуры начала его окисления на $73.8-122.6^{\circ} \mathrm{C}$. Удельный тепловой эффект окисления изменялся немонотонно: для образца 3 зафиксировано его максимальное увеличение на $6.24 \%$, а для образцов 2 и 4 снижение на 12.16 и на $5.30 \%$ соответственно. 
Это также является следствием воздействия вихревых токов, которое приводит к увеличению электрического потенциала поверхности частиц и к увеличению адсорбционной способности частиц порошка.

\section{Заключение}

Переменное электромагнитное поле частотой $50 \mathrm{~Hz}$, используемой в промышленности, влияет на порошки алюминия различной дисперсности (микро- и нанопорошки). Установлено, что в результате такого воздействия увеличивается адсорбционная способность поверхности порошков. Это приводит к протеканию целого ряда физико-химических процессов в порошке при действии на него поля: сорбции воды, ее диссоциации, процессам заряжения металлической составляющей частицы порошка и последующему увеличению ее реакционной способности. Наиболее вероятной физической природой этих процессов является инициирование вихревых токов Фуко в металлической составляющей микро- и наночастиц порошков алюминия.

Возможно, этот же механизм приводит к ранее обнаруженному увеличению реакционной способности порошков алюминия при длительном хранении в полиэтиленовой негерметичной таре [16] вследствие неизбежного воздействия различных внешних электромагнитных полей токов промышленной частоты. Таким образом, для улучшения сохранности свойств порошков алюминия различной дисперсности их целесообразно хранить в металлической таре, экранирующей от воздействия различных внешних электромагнитных полей, а также вдали от источников различных излучений.

\section{Финансирование работы}

Работа выполнена при финансовой поддержке Российского фонда фундаментальных исследований, грант № 19-03-00160.

\section{Конфликт интересов}

Авторы заявляют, что у них нет конфликта интересов.

\section{Список литературы}

[1] В.Н. Анциферов, Г.В. Бобров, Л.К. Дружинин. Порошковая металлургия и напыленные покрытия (Металлургия, М., 1987)

[2] Ч. Сеттерфилд. Практический курс гетерогенного катализа (Мир, М., 1984)

[3] Г.К. Боресков. Гетерогенный катализ (Наука, М., 1988)

[4] Энергетические конденсированные системы. Краткий энщиклопедический словарь, под ред. Б.П. Жукова (ЯнусK, M., 2000)

[5] M.W. Beckstead. A Summary of Aluminum Combustion (Belgium, 27-31 May, 2002), and published in RTO-EN-023. P. 1-45.
[6] W.H. Hunt. Inter. J. Powd. Metal., 36, 50 (2000).

[7] F.V. Beaumont. J. Powd. Metal., 6, 41 (2000).

[8] T.A. Khabas. Glass and Ceramics, 59, 404 (2002).

[9] A.V. Korshunov. Russ. J. Phis. Chem., 85, 1202 (2011).

[10] A.V. Korshunov, A.P. Il'In, N.I. Radishevskaya, T.P. Morozova. Russ. J. Phys. Chem. A, 84 (9), 1576 (2010).

[11] H. Ellern. Military and Civilian Pyrotechnics (Chemical Publisher Company Inc., 1968), p. 464.

[12] П. Барре. Кинетика гетерогенных процессов (Мир, М., 1976)

[13] В.Г. Шевченко, В.И. Кононенко, М.А. Булатов, И.Н. Латош, И.А. Чупова, Л.А. Акашев. ФГВ, 34 (1), 45 (1998).

[14] А.В. Мостовщиков, А.П. Ильин, П.Ю. Чумерин, Ю.Г. Юшков. ЖТФ, 88(8), 1259 (2018). [A.V. Mostovshchikov, A.P. Il'in, P.Y. Chumerin, Y.G. Yushkov. Tech. Phys., 63 (8), 1223 (2018).]

[15] A.V. Mostovshchikov, A.P. Ilyin, I.S. Egorov. Radiation Phys. Chem., 153, 156 (2018).

[16] A. Ilyin, D. Tikhonov, A. Mostovshchikov. Propellants, Explosives, Pyrotechnics, 43 (8), 749 (2018).

[17] К. Хауффе. Реакиии в твердых телах и на их поверхности. ч. 1, пер. с нем. (ИЛ, М., 1962), с. 128-151.

[18] А.П. Ильин. Известия Томского политех. ун-та, 306 (1), 133 (2003).

[19] А.Л. Дорофеев. Вихревые токи (Энергия, М., 1977)

[20] W.W. Wendlandt. Themal Methods of Analysis, 2nd ed. (John Wiley \& Sons, NY., 1974) p. 524. 